\title{
Patrimonio digital
}

Jaime Alberto Díaz

\section{Patrimonio digital lato sensu}

En el desarrollo del presente trabajo de investigación se podrá encontrar con la deconstrucción de diversos conceptos que, a saber de los expertos en la materia, podrían considerarse indiscutibles y axiomas inamovibles en la enseñanza de los mismos; sin embargo, el progreso tecnológico en la era de la información ha invitado a buscar que estos conceptos se reconstruyan o bien se flexibilicen en afán de sobrevivir a los cambios incesantes que ocurren en la vida on line. Ejemplo de lo anterior, recae sobre el concepto de patrimonio, que en sus diferentes teorías ha encontrado un debate interminable sobre todo en el mundo del derecho civil, sin embargo, por ahora nos ajustaremos al concepto que nos brinda José Alfredo Domínguez Martínez: “... en términos generales, es el conjunto de bienes, derechos y obligaciones correspondientes a una persona, con contenido económico y que constituyen una universalidad jurídica" (Domínguez, 2008) ${ }^{1}$ (Teoría Clásica). Concepto -y teoría- que se ajusta de forma adecuada a la realidad jurídica que nos enfrentamos en la vida off line, sin embargo, en la vida on line nos existe al hueco dogmático que yace sobre todo aquello que se genera en internet, pues al parecer de los diversos cuerpos normativos (tanto en Derecho Nacional como en Derecho comparado) no es prudente hablar de patrimonio digital desde la perspectiva de derecho privado, de acuerdo al término de patrimonio que nos brinda Domínguez Martínez. 1 DOMÍNGUEZ MARTíNEZ, José Alfredo. Derecho Civil, parte general, personas, cosas
negocio jurídico e invalidez. Editorial Porrúa. Edición 11. Página 215, México, 2008. 
La aproximación más cercana que existe sobre regulación del patrimonio digital lo encontramos en la Carta Sobre la Preservación del Patrimonio Digital (UNESCO, 2003) ${ }^{2}$, en la cual se acuña el término desde la perspectiva del Derecho internacional público, lo que a parecer de este autor, genera un inigualable antecedente para analizar este concepto desde el punto de vista del derecho privado y analizar su composición en la particularidad de los individuos. Así las cosas, en la Carta de referencia, se percibe la preocupación de la Organización de las Naciones Unidas para la Educación, la Ciencia y la Cultura, sobre la posible y muy probable desaparición del patrimonio que se origina en internet; en primer lugar, parten de la máxima que la desaparición de cualquier forma de patrimonio empobrece el acervo de todas las naciones, en segunda posición, la UNESCO considera que la inestabilidad de internet es un riesgo latente para la información y conocimiento acumulado en formato html, es decir, que la información digital está expuesta a la obsolescencia técnica y el deterioro físico. Así las cosas, UNESCO tiene presente la probable desaparición del "patrimonio digital", cómo si éste fuere una especie en la lista de peligro de extinción y proclamó que las naciones debían unir esfuerzos para que generaciones actuales y futuras tengan acceso a este acervo cultural. En tales términos el artículo primero de esta Carta, dicta:

El patrimonio cultural como herencia común.

Artículo 1- Alcance. El patrimonio digital consiste en recursos únicos que son fruto del saber o la expresión de los seres humanos. Comprende recursos de carácter cultural, educativo, científico o administrativo e información técnica, jurídica, médica y de otras clases, que se generan directamente en formato digital o se convierten a éste a partir de material analógico ya existente. Los

\footnotetext{
2 UNESCO. Carta sobre la preservación del patrimonio digital. 15 de octubre de 2003. Versión en español que se puede consultar a través del portal http://portal.unesco.org/es/ev. php-URL_ID=17721\&URL_D0=D0_TOPIC\&URL_SECTION=201.html . Consultado el 29 de mayo de 2017.
} 
productos "de origen digital" no existen en otro formato que el electrónico.

Los objetos digitales pueden ser textos, bases de datos, imágenes fijas o en movimiento, grabaciones sonoras, material gráfico, programas informáticos o páginas Web, entre otros muchos formatos posibles dentro de un vasto repertorio de diversidad creciente. A menudo son efímeros, y su conservación requiere un trabajo específico en este sentido en los procesos de producción, mantenimiento y gestión.

Muchos de esos recursos revisten valor e importancia duraderos, y constituyen por ello un patrimonio digno de protección y conservación en beneficio de las generaciones actuales y futuras. Este legado en constante aumento puede existir en cualquier lengua, cualquier lugar del mundo y cualquier campo de la expresión o el saber humanos. ${ }^{3}$

La primera distinción que es prudente analizar del bello párrafo que nos brinda la Organización de las Naciones Unidas, es el doble origen que podría existir sobre el patrimonio digital. Esto es, tenemos los recursos que se han generado en formato digital y que no existen de forma material, más allá de lo que conocemos en la red de redes, por otro lado, contamos con los recursos de origen tradicional y que han sufrido una transformación digital, sin que necesariamente implique la desaparición del formato analógico (tradicional). La segunda disección que es prudente realizar sobre el primer artículo de la Carta, es que, a pesar de la creencia popular de la "infinita" estabilidad de los recursos digitales, es sabido que estos también pueden desaparecer y, en algunas ocasiones, con mucha mayor velocidad que los recursos analógicos. Es decir, es inverosímil afirmar que internet tiene memoria perpetua, dado que si bien es cierto, el origen digital de los mismos permite un mejor almacenamiento, distribución y reproducción, no debemos dejar fueras aquellas plataformas o dispositivos que están diseñados con "memoria

3 Op. cit., 2 
temporal selectiva", tal como los archivos temporales (cookies) de navegación o aplicaciones cómo lo son Snapchat.

Hasta este punto, quizá no logré convencer a mi lector de la relevancia sobre la protección del patrimonio digital, sin embargo, en el año 2013, la empresa de tecnología y desarrollo CISCO emitió una infografía sobre las estimaciones de cantidad de recursos, datos e información que existía en internet. A saber, nos dejó clara la desaparición de medidas tradicionales de almacenamiento de información para comenzar a hablar sobre Petabyte, Exabyte, Zettabyte y Yottabyte (CISCO, 2004) ${ }^{4}$ :

Tabla 1

\begin{tabular}{|l|l|l|}
\hline Término de tráfico & Es equivalente a & \multicolumn{1}{c|}{ ¿A cuánto equivale? } \\
\hline 1 Petabyte & $\begin{array}{l}\text { 1,000 Terabytes o } \\
250 \text { mil DVD's }\end{array}$ & $\begin{array}{l}\text { 480 Terabytes significan una } \\
\text { biblioteca digital con todos los } \\
\text { libros catálogos del mundo en } \\
\text { todos los idiomas }\end{array}$ \\
\hline 1 Exabyte & $\begin{array}{l}1,000 \text { Petabytes ó } \\
250 \text { millones de } \\
\text { DVD's }\end{array}$ & $\begin{array}{l}\text { exabytes son equivalentes } \\
\text { a la transcripción de todas las } \\
\text { 400 exabytes es la cantidad } \\
\text { de información que cruzó en } \\
\text { internet, sólo en el año 2012 }\end{array}$ \\
\hline 1 Zettabyte & $\begin{array}{l}1,000 \text { Exabytes ó } \\
250 \text { billones de } \\
\text { DVD's }\end{array}$ & $\begin{array}{l}\text { Es equivalente a la cantidad } \\
\text { de información que ha cruzado } \\
\text { internet desde su creación }\end{array}$ \\
\hline 1 Yottabyte & $\begin{array}{l}1,000 \text { Zettabytes } \\
\text { o 250 trillones de } \\
\text { DVD's }\end{array}$ & $\begin{array}{l}\text { 20 Yottabytes equivalen a una } \\
\text { fotografía instantánea de la } \\
\text { superficie entera del planeta } \\
\text { Tierra }\end{array}$ \\
\hline
\end{tabular}

4 CISCO. Visual Networking Index (VNI) IP Traffic Chart. Consultada en línea a través del vínculo http://www.cisco.com/cdc_content_elements/networking_solutions/service_provider/visual_networking_ip_traffic_chart.html el pasado 31 de mayo de 2017. Es importante destacar que, para este estudio la compañía tomó como referencia la base de estimaciones hasta 2006 realizada por la University of Pennsy/vania School of Medicine, los datos del profesor Roy Williams, expuestos en su artículo "Data Powers of Ten", del año 2000 y el resto, se reprodujo de las opiniones expertas emitidas en el VNI 2013. 
Entre otras estadísticas de la compañía CISCO, destacan las que compiló en junio de 2016 en el marco del Cisco Visual Networking Index (VNI), en la que afirma que para el año 2020: i) tomaría más de 5 millones de años mirar la totalidad de videos que se han subido a internet; ii) el número de dispositivos conectados a la red superarán en más de tres veces la cantidad total de población humana; y iii) La información que para el año 2016 hubo superado el primer Zettabyte, se triplicaría y alcanzaría, al menos los 2.3 Zettabytes (CISCO, 2004) ${ }^{5}$. Si a estos parámetros incluimos que, en realidad, la tendencia de creación y almacenamiento hoy en día se realiza preferentemente en internet, descubriremos que estamos en un punto medular en la construcción de historia y antropología moderna; para sustentar lo anterior, invocaré el estudio que realizó la Asociación Mexicana de Internet en colaboración con INFOTEC, en el que destaca que los cibernautas mexicanos comienzan a interactuar en la red a partir de los 3 años y que la cultura de los Estados Unidos Mexicanos es permanecer al menos 8 horas del día conectado a la web, preferentemente a redes sociales como lo son Facebook y Youtube (AMI/ INFOTEC, 2017) ${ }^{6}$. Estos datos no son números aislados de la realidad y que reflejan el interés de otras latitudes, toda vez que, si se advierte que los mexicanos pasamos el 50\% de nuestro día productivo en línea, así como lo hacen ciudadanos de otras partes del mundo, esto también implica que el tráfico de datos que ocurre, así como el nivel de creación, es superior, inclusive, sobre lo que se realiza en recursos analógicos. Bajo esta premisa mayor, la UNESCO comprendió la problemática y la formuló ante las naciones

\footnotetext{
5 CISCO. The Zettabyte Era- Trends And Analysis. Documento que forma parte del CISCO @ Visual Networking Index (VNI). Consultado en línea el 31 de mayo de 2017 a través de http:// www.cisco.com/c/en/us/solutions/collateral/service-provider/visual-networking-index-vni/ vni-hyperconnectivity-wp. html

6 Asociación de Internet.Mx/ INFOTEC. $13^{\circ}$ Estudio sobre los hábitos de los usuarios de Internet en México 2017. Mayo 2018. Consultado en línea a través del vínculo https:// www.infotec.mx/work/models/infotec/Resource/1012/6/images/Estudio_Habitos_Usuarios_2017.pdf el pasado 31 de mayo de 2018.
} 
involucradas: ¿qué haríamos si internet, de pronto, decide que toda la información que hasta ahora se ha almacenado debe desaparecer? Indiscutiblemente ello traería aparejada la desaparición de miles de exabytes que acreditan el paso del hombre por la tierra. Nuestros antepasados lucharon por dejar en medios analógicos su historia, su progreso y su aportación a la humanidad, ya que no siempre contaron con los mejores mecanismos para brindar evidencia del proceso de creación que atravesaron para llegar al puerto de destino; tallarlo en roca, madera, inclusive en papel, ahora parece absurdo cuando se tiene al alcance de un golpe de ratón, internet y las tecnologías de la información y la comunicación, empero, esto no hace que este medio de almacenamiento sea igual de efímero e inestable que otra -anterior- forma de comunicación creada por el hombre. En caso de que internet y los datos en él almacenados hasta el día de hoy desaparecieran, ello implicaría llevarse consigo la historia de la humanidad y su evolución al menos de los últimos lustros. Así lo sostuvo la organización de referencia en el artículo $3^{\circ}$ de la Carta, a saber:

Artículo 3 - El peligro de pérdida.

El patrimonio digital del mundo corre el peligro de perderse para la posteridad. Contribuyen a ello, entre otros factores, la rápida obsolescencia de los equipos y programas informáticos que le dan vida, las incertidumbres existentes en torno a los recursos, la responsabilidad y los métodos para su mantenimiento y conservación y la falta de legislación que ampare estos procesos.

Los cambios en las conductas han ido a la zaga del progreso tecnológico. La evolución de la tecnología digital ha sido tan rápida y onerosa que los gobiernos e instituciones no han podido elaborar estrategias de conservación, oportunas y bien fundamentadas. No se ha comprendido en toda su magnitud la amenaza que pesa sobre el potencial económico, social, intelectual y cultural que encierra el patrimonio, sobre el cual se edifica el porvenir. ${ }^{7}$

7 UNESCO, op. cit., 2 


\section{Patrimonio digital strictu sensu}

Con independencia del temor globalizado que ha establecido UNESCO, la preocupación que enfrentamos los particulares, alejados tanto del concepto de patrimonio digital (lato sensu) como de las intenciones de conservación a qué hace referencia la Carta sobre la preservación del patrimonio digital, es que ésta, se desvía de la protección de los bienes y derechos de los particulares, sobre todo si estos son considerados con bajo mérito cultural para que resulte digna su protección para la posteridad. Así lo sostiene, a contrariu sensu, la propia declaratoria, cuyo texto literal prescribe:

Artículo 7 - Seleccionar los elementos que deben conservarse.

$\mathrm{Al}$ igual que ocurre con el conjunto del patrimonio documental, los principios de selección pueden diferir de un país a otro, aun cuando los principales criterios para determinar los elementos digitales dignos de conservación sean su significado y valor duraderos en términos culturales, científicos, testimoniales o de otra índole. Indudablemente, se deberá dar prioridad a los productos "de origen digital". Los procesos de selección y de eventual revisión subsiguiente han de llevarse a cabo con toda transparencia y basarse en principios, políticas, procedimientos y normas bien definidos. ${ }^{8}$

Fundameto que permite evidenciar la hipótesis sostenida en el presente capítulo, ya que parecería que los Estados tienen un poder absoluto para determinar qué -bajo un subjetivo análisis gubernamental- elementos digitales son dignos de conservarse; siendo el único criterio objetivo, el "origen digital" que estos deben tener para ser considerados aptos para esta arca de Noé digital. Quizá se podría debatir el punto de vista que coloco en manos del lector, bajo la noción de que los Estados se encuentran obligados a determinar principios, políticas y procedimientos para el almacenamiento de referencia,

8 UNESCO, op. cit.. 2 
empero, hasta hoy en día no existen normas que en derecho positivo permitan identificar las obras o recursos que alcanzarán el mérito solicitado. Sin conceder oportunidad al anterior argumento, cabe destacar que esto inclusive resulta violatorio de Derechos Humanos si es que se sostiene la revisión de Derechos de Autor sobre los recursos creados; ya que la legislación de los diversos Estados que se encuentran adscrito al Convenio de Berna, que administra la Organización Mundial de la Propiedad Intelectual, no permitan la valoración "subjetiva" de las entidades encargadas de la protección de las prerrogativas a favor de los autores, más allá de considerar si ésta es original y se fijó en un soporte material o electrónico susceptible de reproducción.?

La tesitura sostenida por la UNESCO resulta confusa y excluyente bajo las razones de derecho expuestas, máxime si sometemos a consideración de esta organización, el patrimonio digital particular que se hubiese generado y que, a saber de las entidades gubernamentales no cuenta con el mérito suficiente para ser susceptible de la protección que sugieren las naciones. Tal parecería que un examen subjetivo y burocrático podría borrar de la historia humana, el patrimonio que los individuos generan en internet de forma consuetudinaria, en perjuicio de los individuos. A consideración del lector, quisiera compartir algunas reflexiones sobre Patrimonio Digital en Sentido Estricto, mismas que permitirán fortalecer la hipótesis sostenida.

\footnotetext{
9 Así lo sostiene el artículo $5^{\circ}$ del Convenio de Berna, cuyo inciso 2) sostiene que el goce y el ejercicio de los derechos reconocidos por el propio Convenio y la legislación de cada país, no se podrá subordinar a ninguna formalidad. Máxime que el propio Convenio, en su artículo $1^{\circ}$, prescribe que se considerará "original" cualquier obra de las catalogadas por dicho Tratado Internacional. Es decir, que la originalidad de la obra se concederá en atención de la calidad de la creación que se ostente como obra, único elemento de discreción permitido por la materia, sin que sea permisible la aplicación de criterios administrativos que pudieren condicionar el ejercicio de derechos de autor, derivados de la obra. Puede consultar el texto íntegro del Convenio de Berna, vigente a partir del año 1984, derivado del Acta de París del 24 de julio de 1971, a través del vínculo http://www.wipo.int/treaties/es/ip/berne/ Consultado en línea el 01 de junio de 2017.
} 


\section{II.1. Datos biométricos}

El diccionario de la Real Academia Española define a la "biometría" como el estudio mensurativo o estadístico de los fenómenos o procesos biológicos, sin embargo, me gustaría invocar el concepto de "biometría informática" que acuñó la compañía multinacional, Aware Inc., en la que indica que la biometría es la autenticación física y lógica de las personas en controles de acceso, así como el reconocimiento casi en tiempo real de sospechosos de un control fronterizo; asimismo, precisa que la biometría persigue 3 fines fundamentales: 1) verificación, 2) identificación y, 3) control de duplicados. Derivado del mismo estudio, la compañía Aware Inc., precisa que debemos comprender por datos biométricos: “...se refieren a las características físicas (y conductuales) más propias de cada uno, que pueden ser detectadas por dispositivos e interpretadas por computadoras de modo que pueden usarse como nuestros representantes en el ámbito digital..." (Aware, 2017) ${ }^{10}$. Esto permite generar una base de datos que vincula al usuario con una serie de datos personalísimos, que le brinda verificación, identificación y control para el acceso a plataformas y ejecución de procesos. Hasta este punto, se presentan 3 niveles de utilización de los datos biométricos. En primer lugar, tenemos la verificación, que consiste en realizar comparación biométrica entre los nuevos datos proporcionados por el usuario que pretende tener acceso a un equipo, aplicación informática o base de datos y el dato biométrico anteriormente proporcionado y que se señaló como referencia autorizada de acceso; el dato biométrico sustituye el password o PIN, de tal suerte que si el nuevo dato biométrico coincide con el que se encuentra almacenado en el equipo (base central o teléfono inteligente); la comparación que se ejecuta en este tipo de procesos es conocida como "uno a uno". La identificación biométrica opera de manera similar, sin

\footnotetext{
10 Aware. ¿Qué es la biometría?- Documentos Informativos. Aplicaciones biométricas. Consultado en línea el 01 de junio de 2017, a través del vínculo https://www.aware.com/ es/que-es-la-biometria/aplicaciones-biometricas/
} 
embargo, la comparación del nuevo dato biométrico no ocurre sobre una plantilla única almacenada, sino que la equivalencia se realiza sobre una base de datos (Big Data); es decir, en el proceso de identificación se aplican más de un dato biométrico y a su vez, estos son analizados y comparados -mediante procesos lógico matemáticos- a una base de datos centralizada que permiten definir si el usuario que se pretende autenticar, es la persona que dice ser; a esto se le llama comparación "uno a muchos". Por último, el control de duplicado consiste en la comparación de bases de datos -biométricos- con otras bases, en afán de eliminar la duplicidad de usuarios y evitar posibles fraudes digitales.

La utilización de datos biométricos para operar equipos de alta tecnología se encontraba reservada para empresas y grandes corporativos, sin embargo, la individualización, disminución de costos y la reducción de la tecnología permitió que cualquier propietario de un teléfono inteligente contara con esta herramienta en sus manos, así también, debió alimentar su equipo o algún servidor central con la información biométrica suficiente para lograr acceder al mismo, sin que, en muchos de los casos conozcan cómo es que se resguarda esa información por los fabricantes del hardware o los desarrolladores del software. Sin embargo, algunas compañías ya han comenzado a mostrar interés en el blindaje de los datos que se almacenan en los equipos telefónicos particulares o bien, que se generan a través de estos, tal es el caso de Samsung quién lanzó una gama de productos de seguridad de datos llamados Device Encryption y On Device Encryption (Samsung, 2016) ${ }^{11}$, que ofrecen seguridad tanto a empresas como a particulares, para proteger los datos sensibles que pudieran vulnerarse.

Desde la panóptica jurídica, la Ley Federal de Protección de Datos Personales en Posesión de Particulares (México, 2010)

\footnotetext{
11 Samsumg. Soluciones para dispositivos Móviles. Encriptación de datos. Consultado el 01 de junio de 2017 a través del vínculo http://www.samsung.com/es/business/solutionsservices/mobile-solutions/security/encryption
} 
reviste suma importancia a los datos personales, especialmente a aquellos de carácter sensible, mismos que se definen en el artículo 3, cuyas fracciones V y VI a la letra indican:

Artículo 3 - Para los efectos de esta Ley, se entenderá por:

V. Datos personales: Cualquier información concerniente a una persona física identificada o identificable.

VI. Datos personales sensibles: Aquellos datos personales que afecten a la esfera más íntima de su titular, o cuya utilización indebida pueda dar origen a discriminación o conlleve un riesgo grave para éste. En particular, se consideran sensibles aquellos que puedan revelar aspectos como origen racial o étnico, estado de salud presente y futura, información genética, creencias religiosas, filosóficas y morales, afiliación sindical, opiniones políticas, preferencia sexual. (CDHCU, 2010) ${ }^{12}$

La aproximación legal que se invoca, nos permite comprender que los datos biométricos son de naturaleza sensible y constituyen parte del patrimonio digital que de forma voluntaria o involuntaria, generan los usuarios en internet. Independientemente de su fuente volitiva, existe obligación de los fabricantes y desarrolladores de software, de indicar el fin del almacenamiento de los datos biométricos, así como la forma en que serán almacenados.

\section{II.2. Datos personales}

En seguimiento a la cadena de protección que debe existir en los dispositivos de comunicación, hay un nivel menos complejo aunque igual de sensible que los datos biométricos; hablamos del nombre, iconografías de nuestra propia imagen, usuarios y datos generales de identificación como lo podrían

\footnotetext{
12 Cámara de Diputados del H. Congreso de La Unión. Ley Federal de Protección de Datos Personales en Posesión de los Particulares. Expedida el 05 de julio de 2010. Se puede consultar el texto íntegro de la ley, a través del vínculo http://www.diputados.gob.mx/LeyesBiblio/ pdf/LFPDPPP. pdf
} 
ser edad, sexo, religión, preferencia política, filosófica o moral, así como los nickname, user name y contraseñas (password) que solicitan las plataformas para iniciar la navegación en cualquiera de sus modalidades. Tal como se indicó con anterioridad, los cibernautas invierten una gran cantidad de horas productivas en internet y del tiempo invertido, mayormente se disfruta la navegación en redes sociales como Facebook, Whatts App, Twitter o Youtube. ${ }^{13}$ Específicamente, el 97\% de los usuarios mexicanos navegan en la web para acceder a la red social denominada Facebook, por lo cual se advierte que se genera a cargo de esta plataforma responsabilidad de tratamiento sobre los datos personales que pudiere generar consecuencias de derecho. A efecto de lo anterior, invocaremos el concepto de Base de Datos, Encargado, Responsable y Tratamiento de la Ley Federa de Protección de Datos Personales:

Artículo 3 - Para los efectos de esta Ley, se entenderá por:

II. Bases de datos: El conjunto ordenado de datos personales referentes a una persona identificada o identificable.

IX. Encargado: La persona física o jurídica que sola o conjuntamente con otras trate datos personales por cuenta del responsable.

$\cdots$

XIV. Responsable: Persona física o moral de carácter privado que decide sobre el tratamiento de datos personales.

XVIII. Tratamiento: La obtención, uso, divulgación o almacenamiento de datos personales, por cualquier medio. El uso abarca cualquier acción de acceso, manejo, aprovechamiento, transferencia o disposición de datos personales.

13 Op. cit., 6 
Si para ello somos meticulosos, resulta necesario hacer una revisión a las políticas, términos y condiciones de cada una de las redes sociales en las cuáles tenemos acceso, así como del propio buscador Google, que ha determinado reglas generales para aquellos que ocupen sus servicios, así como lo de sus plataformas filiales. Al respecto, realizaremos las consideraciones necesarias en el capítulo respectivo dentro de la presente obra.

En términos generales, se advierte que no sólo los mecanismos que permiten a las plataformas identificar a la interfaz humana mediante elementos legalmente reconocidos, son los considerados datos personales, sino que esto también pudiere englobar nombres de usuario y contraseñas -inclusive bancarias- entre los datos personales de carácter sensible pero de naturaleza digital. Datos que hoy en día poseen un valor económico en el black market y deep web por las infinitas posibilidades ilícitas de su mala utilización.

\section{II.3. Identidad y reputación digital}

Tal como lo reconoce el Maestro Francisco José Santamaría Ramos, de la Universidad Complutense de Madrid, la "existencia paralela entre la vida física y la vida virtual genera que las personas físicas y jurídicas deban producir lo que hoy se conoce como identidad digital, que deriva en la reputación digital" (Santamaría, 2015) ${ }^{14}$. Sin embargo, han sido pocas las instituciones que han dedicado su tiempo y esfuerzo académico a estudiar las consecuencias de un mal manejo de la reputación digital y cómo es que ésta se puede destruir en cuestión de segundos. Verbigracia, en noviembre del año 2016, la marca internacional y productora de anteojos/lentes conocida como Hawkers ${ }^{\mathrm{TM}}$ lanzó un tuit en apoyo a Donald Trump, triunfador y ahora presidente de los Estados Unidos de América: "Mexicanos, pónganse estos lentes para que no se les noten los ojos hinchados

\footnotetext{
14 SANTAMARÍA Ramos, Francisco José. Identidad y Reputación Digital. Visión Española de un Fenómeno Global. Revista Ambiente Jurídico. Número 17. Enero 2015
} 
mañana en la construcción del muro (sic)"15. Ante el ritmo social y la preocupación mundial que existió, sobre la posible elección de un candidato que había manifestado abiertamente su animadversión a los inmigrantes, sobre todo aquellos de origen hispano-latinoamericano, asimismo, demostrar su alta intención de excluir de diversos tratados internacionales a la nación americana ${ }^{16}$, provocó que la marca fuere duramente atacada durante las elecciones y que, a pesar del terror colectivo que se sufría en redes sociales (\#eleccionesUSA, \#elecciones2016), colocarse en la tendencia y, finalmente, culminar con la reacción del piloto mexicano de Fórmula 1, Sergio "Checo" Pérez, quién a través de su cuenta oficial en Twitter dictó que rompía relaciones con la marca Hawkers por atentar contra el pueblo mexicano y los ideales que los identificaban como nación. Al respecto, la marca de lentes culpó al CM (Community Manager) de la Ciudad de México y se vio obligada a desplegar un comunicado en uno de los diarios de mayor circulación nacional para disculparse con los mexicanos, debido al desafortunado mensaje. Posteriormente, ofreció al piloto mexicano la creación de una fundación en apoyo a niños en

15 El tuit original fue eliminado de la cuenta oficial en Twitter de Hawkers, sin embargo, la campaña que se lanzó en contra de la compañía le generó pérdidas millonarias y que hoy en día, sea una de las marcas con peor reputación digital en el mercado mexicano. Puede consultar la historia y artículo completo, a través del diario en línea El Huff Post, La empresa Hawkers paga muy cara una broma sobre Trump en Twitter, Internacional, Redacción, 10 de noviembre de 2016, disponible en la red a través del vínculo http://www.huffingtonpost.es/2016/11/10/hawkers-trump_n_12894462.html, consultado el 03 de junio de 2017.

16 A la fecha de redacción de la presente obra, el presidente electo Donald Trump, ha determinado que los Estados Unidos de América quedan excluidos del Acuerdo de Asociación Transpacífico y, recientemente, anunció que abandonará el Acuerdo de París sobre cambio climático, a lo que el mundo respondió: \#MakeThePlanetGreatAgain. Para mayores referencias, puede consultar Donald Trump anuncia que Estados Unidos abandonará el Acuerdo de París sobre cambio climático (BBC mundo, 01 de junio de 2017 http://www. bbc.com/mundo/noticias-internacional-40124921 ) y Trump retira a Estados Unidos del tratado comercial con el Pacífico (BASSETS, Marc. El País, Enero 2017 http://internacional.el pais.com/internacional/2017/01/23/estados_unidos/1485184656_242993.html ) 
situación de calle, que llevaría su nombre: "Fundación Querido Sergio x Hawkers", con una inversión inicial de 500 mil pesos y aportaciones anuales superiores al millón de pesos. ${ }^{17}$

En seguimiento a lo expuesto, el autor Carlos Pinzón, encargado del área Social Media para la firma española Invenio PRO, señala que existe diferencia entre la identidad digital y la reputación digital, en el entendido que la segunda es consecuencia de la primera. Así, la identidad digital es:

... lo que nosotros mismos vamos creando en internet. Cuando subimos una foto a Facebook, cuando enviamos un tuit con un comentario o cuando detallamos nuestro currículum en Linkedin, nos estamos forjando una identidad digital que nos está describiendo (sic) (PINZÓN, 2013) $)^{18}$

En un sentido amplio, señala Pinzón, la identidad digital constituye la referencia y percepción que poseo de mi persona y cómo lo reflejo en la red de redes, en pocas palabras, "lo que yo digo de mí". La reputación digital, por otro lado, se construye de la dualidad entre lo que se controla y la información que un titular legítimo sube a la web con la intención de generar una percepción favorable de sí mismo y, por las valoraciones subjetivas que realizan los usuarios en internet que han interactuado con mi persona, perfil o producto. Es decir, es la consecuencia de la ejecución de la identidad digital y los comentarios, opiniones, valoraciones y juicios de valor que se realizan por los cibernautas en correspondencia con lo que se dijo que "somos".

17 FORBES. Hawkers propone a Checo Pérez crear una fundación con su nombre. Portada. Últimas Noticias. Forbes Staff. Noviembre 17 de 2016. Se puede consultar en línea a través del vínculo https://www.forbes.com.mx/hawkers-propone-a-checo-perez-crear-una-fundacioncon-su-nombre/ Mismo que se revisó el 03 de junio de 2017.

18 PINZÓN, Carlos. Diferencia entre identidad digital y reputación on-line. INVENIO PRO. Social Media. INVENIO PRO, Blog de Marketing Online. Junio 02013. Consultado en línea a través del vinculo http://www.inveniopro.es/diferencia-entre-identidad-digital-y-reputacion-on-line/, el 03 de junio de 2017. 
En breves términos, la reputación digital es "lo que los demás dicen de mí" en la vida on line. ${ }^{19}$

Sin duda, los conceptos anteriormente descritos permiten advertir que la identidad y reputación digital no son elementos exclusivos de las personas físicas, sino que esto también afecta a las personas jurídicas. Sin embargo, a la aplicación de estas figuras cibernéticas en el ámbito de las corporaciones se les conoce como reputación empresarial. Al respecto, el concepto jurídico más aproximado a las hipótesis expuestas, se encuentra excelsamente definido por el diccionario legal de Black, mismo que define Online Corporate Reputation como la percepción que tienen los usuarios de internet sobre la empresa. De manera general -señala el diccionario legal en cita- se obtiene de blogs, foros públicos y artículos en la web. Y para sorpresa del autor y de algunos de mis lectores, ya incluye en su concepto la precisión de Reputation Management, considerándole como el servicio que puede influenciar la reputación online al redireccionar comentarios negativos y promover mensajes positivos a favor de la Empresa. ${ }^{20}$ En ese tenor, el Reputation Institute publica de forma anual el índice de las marcas y compañías con mejor reputación en el mundo, entre las que incluye a marcas globales como BMW, Google, Nike, Microsoft e INTEL, para lo cual utiliza diversos factores de evaluación, como lo son calidad de productos, valor de la marca, posición en el mercado bursátil y determinante, la referencia que existe entre los cibernautas sobre la compañía. ${ }^{21}$

19 Op. cit., 18

20 BLACK'S LAW DICTIONARY. The Law Dictionary. What is Online Coporate Reputation? Puede consultar la definición en inglés, a través del vínculo http://thelawdictionary.org/ online-corporate-reputation/

21 Tan sólo en el año 2016, las 5 marcas mejor posicionadas lo fueron: 1) Rolex: 80.38, 2) Lego: 79.4, 3) Walt Disney: 79.2, 4) Cannon: 78.3 y 5) Google: 78.2. Puede consultar más información y el estudio completo con las 100 empresas mejores posicionadas a nivel global, así como los parámetros íntegros, a través del vínculo (REPutATION INSTITUTE. https:// www.reputationinstitute.com/research/Global-RepTrak-100.aspx Consultado el 03 de junio de 2017. 
Debo someter a consideración del lector el concepto de identidad digital y reputación digital, dentro del universo de lo conocido como Internet 2.0 (Web 2.0), no sólo como un factor dentro del patrimonio digital que pudiere generar consecuencias de carácter comercial, sino también de carácter profesional o laboral, bajo la modalidad de contratación conocida como "Reclutamiento 2.0", la cual consiste en la aplicación de redes sociales como herramienta de selección para las áreas de recursos humanos, en la cual se realiza una búsqueda entre perfiles laborales como es LinkedIn y se compara con lo que se encontró sobre el candidato en una red social más coloquial y flexible como lo es Facebook. En palabras del Maestro Pedro Rojas, este proceso permite a los departamento de RRHH "una aproximación muy estrecha a la persona y una cantidad de datos que nunca hubiesen obtenido usando métodos tradicionales, ya que los perfiles en redes sociales...dejan ver... dentro del interior del candidato potencial" (ROJAS, 2010) ${ }^{22}$; ello pudiendo beneficiar el proceso de selección si es que el interesado cuenta con una buena reputación digital o bien, impidiendo la contratación del mismo y quizá, hasta bloquear su posible selección para otros procesos, en caso de no contar con una buena reputación on line.

Por último, es meritorio para el valor académico de la presente obra, aseverar que el concepto de reputación no es un elemento aislado de la ciencia jurídica ni de los tribunales. En términos del artículo 1916 del Código Civil Federal (México) se advierte que:

“...Por daño moral se entiende la afectación que una persona sufre en sus sentimientos, afectos, creencias, decoro, reputación, vida privada, configuración y aspectos físicos, o bien en la consideración que de sí misma tienen los demás. Se presumirá que hubo daño moral cuando se vulnere o menoscabe ilegítimamente la libertad o la

22 ROJAS, Pedro. Reclutamiento y Selección 2.0. La nueva forma de encontrar talento. Editorial UOC. España 2010. 
integridad física o psíquica de las personas..." (El énfasis es añadido).

Así las cosas, se advierte que el aspecto "moral" de las personas, así como los elementos que definen sus derechos de personalidad se integran, entre otros, por la reputación. Este concepto no debe interpretarse más allá de lo previsto en el propio precepto, sin embargo, el afirmar que la reputación digital forma parte de esa integración personalidad-persona, permitiría argüir violaciones en contra de esa esfera jurídica, en tratándose de conductas que pudieran afectar dicha condición humana en la red de redes, sobre todo, aquellas que podrían viralizarse gracias al poder de las redes sociales.

\section{II.4. Bienes de origen exclusivamente digital}

La corriente de derecho que tradicionalmente separaba a los bienes en tangibles (materiales) o intangibles (inmateriales) se ha visto superada por el acelerado crecimiento de la red de redes, así las cosas, hoy en día se debe hablar que en la categoría de los intangibles debemos comprender a aquellos de naturaleza digital por nacimiento y los digitales por transformación. Los primeros, son aquellos que han nacido en el ciberespacio y sólo pueden ser concebido, apreciados y "enajenados" dentro del propio universo digital, en tanto que los segundos corresponden a una categoría de bienes que en origen fueron materiales, empero, que la necesidad y probable desaparición del soporte generó la necesidad de digitalizarlos, así nacieron a la vida en internet y en tanto el documento base original exista, éste no será considerado como el referente y evidencia única de la existencia de un hecho o acto jurídico. En palabras de la Maestra Adrian Porcelli, los bienes inmateriales son intangibles "como las ideas, costumbres, conocimientos, creencias, lenguajes, tradiciones, saberes, formas de expresión, artes o técnicas genéricamente abstractas...", en tanto que los bienes digitales son "todos aquellos bienes culturales y no culturales que tienen forma digital, que están compuestos por ceros 
y unos y que las computadoras se encargan de interpretar y presentarlos en forma de información" (Porcelli, 2015) ${ }^{23}$. Dentro de los ejemplos que nos brinda la renombrada catedrática del Departamento de Ciencias Sociales de la Universidad Nacional de Luján, se encuentran los programas de cómputo, imágenes, música, sitios web, textos, libros y vídeos.

Lo anteriormente expuesto rompe el paradigma que tradicionalmente se ha comprendido sobre la concepción de bienes. Si tomamos como referencia el mundo de los libros digitales (bienes inmateriales digitales) de origen, Amazon representa el $70 \%$ del mercado de las obras literarias electrónicas. Esto ha permitido un acelerado crecimiento en la distribución y venta de estos ejemplares. Para el año 2010, se habían vendido 11 millones de lectores de libros digitales, de los que el 41.5\% fueron Kindles de Amazon, lo que generó y permitió un crecimiento paralelo del estudio en formatos no tradicionales. Sin embargo, este sería un ejemplo sencillo de asimilar dentro del metaverso de posibilidades, ya que casos como la creación de videojuegos similares a Second Life, permite no sólo la creación de un avatar $^{24}$, sino que éste comience a generar

23 Porcelli, A. Los bienes digitales y el derecho de autor en internet. La denominada "piratería informática". Revista del Departamento de Ciencias Sociales, Volumen 2, Número 3. 258.294. Revista electrónica del Departamento de Ciencias Sociales de la Universidad Nacional de Luján. 2015. Puede consultar el texto íntegro a través del vínculo http://www.redsocialesunlu. net/wp-content/uploads/2015/06/RSOC009-16-ARTICulo-PORCELLI.pdf Consultado el 03 de junio de 2017.

24 Si bien el diccionario de la Real Academia Española brinda diversas acepciones, entre ellas "reencarnación o transformación", éstas se alejan del significado que ha obtenido en el ciberespacio. A parecer del autor, el concepto más adecuado a la realidad digital, se desprende del texto publicado por la Universidad Tecnológica Metropolitana de Santiago de Chile, mismo que define al avatar como "una especie de caricatura de un ser de carne y hueve que no sirve para ridiculizarle, sino para localizar el lugar exacto en que ese ser humano se encuentra representado en el ciberespacio. Son representaciones gráficas de los personajes escogidos para representar a los usuarios en el entorno virtual" (Ferrada Cubillos, Mariela. Términos de uso frecuente en la Web Social. Glosario. Departamento de Gestión de Información. Universidad Tecnológica Metropolitana. Serie bibliotecología y gestión de información número 81, Abril 2013. Mismo que se puede consultar en línea a través del vínculo http:// eprints.rclis.org/19182/1/Serie\%20N\%C2\%B081\%20Mariela\%20Ferrada.pdf. 
su propia reputación y, en ciertos casos, sus propios bienes; sin embargo, nadie esperaba que pronto este juego de realidad aumentada resultara del interés de las marcas y patrocinadores, quienes en poco tiempo detectaron el mercado potencial que sería generar product placement sobre la plataforma. Así las cosas, los patrocinadores pronto contactaron a los desarrolladores (Liden Lab) para comenzar un programa de inserción de productos, marcas e inclusive creación de empresas dentro de la propia plataforma, lo que generó derecho de propiedad a favor de un alter ego concebido en la red y por ende, actos y consecuencias de derecho que son susceptibles de un profundo análisis tales como "compraventa de terrenos virtuales" o "arrendamiento de inmuebles para espacios publicitarios"; sin embargo, en afán de ser consecuente con el discurso sostenido hasta ahora, es prudente señalar que estos bienes de origen eminente y exclusivamente digital (incluyendo el avatar), son intangibles que pueden generar un valor económico a favor de la persona jurídica que los opere en el mundo tangible. Hasta este punto, podría ocurrir la hipótesis en la cual existan conflictos entre personas físicas y avatares, avatares y avatares o bien personas morales y avatares; asimismo, podría considerarse que el patrimonio de bienes intangibles digitales cuyo dominio le "pertenece" al avatar fuere superior en valor económico de aquel que posee la persona física que lo opera.

A esta lista de posibles fortunas virtuales, podríamos sumar el ejemplo de los bitcoins y los nombres de dominio, los cuales también constituyen parte del patrimonio digital, sin embargo, estos serán analizados de forma puntual dentro del capitulado de la presente obra.

\section{II.5. Una probable definición de patrimonio digital desde la perspectiva de derecho privado}

En el año 2003, como consecuencia de la Carta Sobre la Preservación del Patrimonio Digital, la División de la Sociedad de la Información, de la UNESCO, a través de la Biblioteca 
Nacional de Australia, prepararon el documento denominado "Directrices para la preservación del patrimonio digital", mismo que consta de 176 fojas útiles e insiste en un concepto estricto de patrimonio, desde la perspectiva de derecho internacional público, ya que en su artículo 5.2.1 prescribe que “...el patrimonio digital está constituido únicamente por aquellos que se considera que poseen un valor permanente" ${ }^{25}$, así las cosas, este concepto deja fuera los elementos de patrimonio digital anteriormente citados como lo son: i) datos biométricos, ii) datos personales, iii) identidad y reputación digital, y iv) bienes de origen digital. Patrimonio que está sujeto a consecuencias de derecho, actos de derecho y claro, intereses jurídicos diversos que pudieren reclamarse ante tribunales jurisdiccionales competentes. Así las cosas, sería prudente definir al patrimonio digital strictu sensu como el conjunto de bienes, derechos y obligaciones correspondientes a un usuario, independientemente de su representación en el ciberespacio, que podrían reflejar contenido económico y que constituyen una universalidad jurídica, mismo que debe ser atribuible a la persona física o moral que cuenta con capacidad de goce y ejercicio para interactuar en la red de redes. Aportamos esta definición con el espíritu crítico de contribuir a nuestra ciencia jurídica, sin embargo, debemos resaltar que la intención fundamental del presente capítulo radica en generar consciencia académica, práctica y jurisdiccional por lo que refiere a los bienes con naturaleza intangible $\mathrm{y}$ digital, en el entendido que aquéllos elementos de derecho que tienen origen en la red de redes, también conforman parte del patrimonio. Esto es, resultará procedente, en algún momento histórico-jurídico concebir el concepto de patrimonio como un todo integrado tanto por aquellos bienes cuya percepción $\mathrm{y}$ regulación recaen sobre figuras tradicionales de derecho, así como bienes digitales que no necesariamente se han estudiado

25 UNESCO. Memory of the World. Directrices para la preservación del patrimonio digital. Preparado por la Biblioteca Nacional de Australia. División de la Sociedad de la Información. Puede consultar la versión en español de este documento a través del vínculo http://unesdoc.unesco.org/images/0013/001300/130071s.pdf Visto en línea el 03 de junio de 2017. 
en el derecho positivo. Sin duda, ello también vencería el paradigma de negocios jurídicos que tradicionalmente se han aceptado, por ejemplo: ¿cómo se llevaría a cabo la transmisión de propiedad de un perfil de Facebook?, ¿cómo se considera a las contraseñas y datos generados en redes sociales respecto de la masa hereditaria? Estas incógnitas serán estudiadas en próximos capítulos y en un humilde intento del autor, brindaremos la respuesta que, a nuestro leal entender, pudiere abrir nuevas puertas en la jurisprudencia.

\section{Bibliografía}

1. Domínguez Martínez, José Alfredo. Derecho Civil, parte general, personas, cosas negocio jurídico e invalidez. Editorial Porrúa. Edición 11. Página 215, México, 2008.

2. UNESCO. Carta sobre la preservación del patrimonio digital. 15 de octubre de 2003. Versión en español que se puede consultar a través del portal http://portal.unesco.org/es/ev.phpURL_ID=17721\&URL_DO=DO_TOPIC\&URL_SECTION=201. html . Consultado el 29 de mayo de 2017.

3. CISCO. Visual Networking Index (VNI) IP Traffic Chart. Consultada en línea a través del vínculo http://www.cisco.com/ cdc_content_elements/networking_solutions/service_provider/visual_networking_ip_traffic_chart.html el pasado 31 de mayo de 2017. Es importante destacar que, para este estudio la compañía tomó como referencia la base de estimaciones hasta 2006 realizada por la University of Pennsylvania School of Medicine, los datos del profesor Roy Williams, expuestos en su artículo "Data Powers of Ten", del año 2000 y el resto, se reprodujo de las opiniones expertas emitidas en el VNI 2013.

4. CISCO. The Zettabyte Era- Trends And Analysis. Documento que forma parte del CISCO $®$ Visual Networking Index (VNI). Consultado en línea el 31 de mayo de 2017 a través de http://www.cisco.com/c/en/us/solutions/collateral/serviceprovider/visual-networking-index-vni/vni-hyperconnectivitywp. html

5. Asociación de Internet.Mx/ INFOTEC. $13^{\circ}$ Estudio sobre los hábitos de los usuarios de Internet en México 2017. Mayo 2018. 
Consultado en línea a través del vínculo https://www.infotec. mx/work/models/infotec/Resource/1012/6/images/Estudio_ Habitos_Usuarios_2017.pdf el pasado 31 de mayo de 2018.

6. Organización Mundial de la Propiedad Intelectual. Convenio de Berna, vigente a partir del año 1984, derivado del Acta de París del 24 de julio de 1971, a través del vínculo http://www. wipo.int/treaties/es/ip/berne/ Consultado en línea el 01 de junio de 2017.

7. Aware. ¿Qué es la biometría?- Documentos Informativos. Aplicaciones biométricas. Consultado en línea el 01 de junio de 2017, a través del vínculo https://www.aware.com/es/que-esla-biometria/aplicaciones-biometricas/

8. Samsumg. Soluciones para dispositivos Móviles. Encriptación de datos. Consultado el 01 de junio de 2017 a través del vínculo http://www.samsung.com/es/business/solutionsservices/mobile-solutions/security/encryption

9. Cámara de Diputados del H. Congreso de La Unión. Ley Federal de Protección de Datos Personales en Posesión de los Particulares. Expedida el 05 de julio de 2010. Se puede consultar el texto íntegro de la ley, a través del vínculo http://www. diputados.gob.mx/LeyesBiblio/pdf/LFPDPPP. pdf

10. Santamaría Ramos, Francisco José. Identidad y Reputación Digital. Visión Española de un Fenómeno Global. Revista Ambiente Jurídico. Número 17. Enero 2015

11. El Huff Post, La empresa Hawkers paga muy cara una broma sobre Trump en Twitter, Internacional, Redacción, 10 de noviembre de 2016, disponible en la red a través del vínculo http://www.huffingtonpost.es/2016/11/10/hawkerstrump_n_12894462.html, consultado el 03 de junio de 2017.

12. BBC Donald Trump anuncia que Estados Unidos abandonará el Acuerdo de París sobre cambio climático (BBC mundo, 01 de junio de 2017 http://www.bbc.com/mundo/noticias-internacional-40124921 ) y Trump retira a Estados Unidos del tratado comercial con el Pacífico (BASSETS, Marc. El País, Enero 2017 http://internacional.elpais.com/internacional/2017/01/23/ estados_unidos/1485184656_242993.html)

13. Forbes. Hawkers propone a Checo Pérez crear una fundación con su nombre. Portada. Últimas Noticias. Forbes Staff. Noviembre 17 de 2016. Se puede consultar en línea a través 
del vínculo https://www.forbes.com.mx/hawkers-propone-acheco-perez-crear-una-fundacion-con-su-nombre/ Mismo que se revisó el 03 de junio de 2017.

14. Pinzón, Carlos. Diferencia entre identidad digital y reputación on-line. Invenio Pro. Social Media. Invenio Pro, Blog de Marketing Online. Consultado en línea a través del vinculo http:// www.inveniopro.es/diferencia-entre-identidad-digital-y-reputacion-on-line/, el 03 de junio de 2017.

15. Black's Law Dictionary. The Law Dictionary. What is Online Coporate Reputation? Puede consultar la definición en inglés, a través del vínculo http://thelawdictionary.org/onlinecorporate-reputation/

16. Rojas, Pedro. Reclutamiento y Selección 2.0. La nueva forma de encontrar talento. Editorial UOC. España 2010.

17. Porcelli, A. Los bienes digitales y el derecho de autor en internet. La denominada "piratería informática". Revista del Departamento de Ciencias Sociales, Volumen 2, Número 3. 258.294. Revista electrónica del Departamento de Ciencias Sociales de la Universidad Nacional de Luján. Puede consultar el texto íntegro a través del vínculo http://www.redsocialesunlu.net/wp-content/uploads/2015/06/RSOC009-16-ARTICULO-PORCELLI.pdf Consultado el 03 de junio de 2017.

18. Ferrada Cubillos, Mariela. Términos de uso frecuente en la Web Social. Glosario. Departamento de Gestión de Información. Universidad Tecnológica Metropolitana. Serie bibliotecología y gestión de información número 81, Abril 2013. Mismo que se puede consultar en línea a través del vínculo http://eprints. rclis.org/19182/1/Serie\%20N\%C2\%B081\%20Mariela\%20 Ferrada.pdf )

19. UNESCO. Memory of the World. Directrices para la preservación del patrimonio digital. Preparado por la Biblioteca Nacional de Australia. División de la Sociedad de la Información. Puede consultar la versión en español de este documento a través del vínculo http://unesdoc.unesco.org/images/ 0013/001300/130071s.pdf Visto en línea el 03 de junio de 2017. 